Índice del Número $9 \quad$ Temática: Estudios de la India

\title{
Páginas Preliminares
}

Presentación general del número

Gabriel Martino

Pág. 1-4

Reconocimiento a los evaluadores del Número 9

Graciela Tonon

Pág. 5

\section{Sección Artículos}

La "modernidad" de la imaginación en Jagannātha Paṇditarāja

Oscar Figueroa

Pág. 6-25

Through the looking glass of Bhils-How Markets win what the State has lost in the desert jungles of Western Rajasthan

Bobby Luthra Sinha

Pág. 26-50

UNCLOS and territorialization of the seas: the case of Indian and Pacific

Oceans

Matías Iglesias

Pág. 51-62

India y China, dos escenarios de la política internacional contemporánea

Leonardo Mejía

Pág. 63-94

Rasgos y desafíos de la reciente diplomacia cultural entre India y China

Verónica Noelia Flores

Pág. 95-108

Breve reseña de Camboya, desde la independencia al Khmer Rouge (1953-

1975).

Francisco Franco

Pág. 109-131

Percepción de la Comunidad Universitaria sobre calidad de vida en

Venezuela. El caso Universidad Metropolitana.

Gloria Marina Lopez, Yuherqui Ayari Guaimaro y Magaly Rafaela Couret

Pág. 132-159

\section{Sección Política Internacional}

Introducción a la Sección Política Internacional

Lía Rodríguez de la Vega

Pág. 160-162

Duelo de titanes: tensiones entre India y China

Laura Gatto

Pág. 163-165

La escalada de violencia en Myanmar y su reflejo en la zona Antonella Vittola

Pág. 167-171 


\section{Sección Aportes de Estudiantes}

Visión y audición como medios de conocimiento en Bhagavad Gītā Marina Closs

Los desafíos de la Nueva Ruta de la Seda para India

Bianca Concatti

Pág. 178-187

\section{Sección Reseña y Rescate de Libros}

The Middle Way Getting Its Way

Ana Paula Martins Gouveia

Pág. 188-192

Reseña de La Bhagavad-Gītā. El clásico de la literatura sánscrita y su recepción

Dr. Roberto E. García

Pág. 193-196

Reseña de: Radiografía del hathayoga de Adrián Muñoz.

Luis O. Gómez Rodríguez

Pág. 197-201

Rescate: A través de un sendero Rosas que se Bifurcan

Reseña de Variazioni sulla rosa, de Antonio Catalfamo

Daniel Del Percio

Pág. 202-204 